\title{
SISTEM INFORMASI PENJUALAN INSTRUMENT BEDAH DAN ALAT KESEHATAN PADA PT. ADB
}

\author{
Anisa Yuliani ${ }^{1}$, Mercy Hermawati ${ }^{2}$, Nurfidah Dwitiyanti ${ }^{3}$ \\ ${ }^{1,2,3}$ Universitas Indraprasta PGRI \\ Jalan Raya Tengah No 80, Kelurahan Gedong, Pasar Rebo, Jakarta Timur \\ 1anisayuliani07@gmail.com, ${ }^{2}$ mercy.hermawati@gmail.com, ${ }^{3}$ nurfidah.pulungan@ gmail.com
}

\begin{abstract}
ABSTRAK
Perkembangan Teknologi saat ini berkembang sangat pesat terutama teknologi informasi komputer, mendorong munculnya inovasi baru dalam berbagai penyajian informasi untuk memenuhi kebutuhan seharihari. Dalam hal ini system informasi memiliki kelebihan yang banyak diantaranya dalam penyimpanan data, hemat waktu, lebih efisien, cepat dan tepat . Penelitian ini bertujuan untuk membuat model rancangan system informasi penjualan instrument bedah dan alat Kesehatan pada PT. Anugrah Dharma Bayu yang efisien efektif dan membantu karyawan perusahaan dalam melakukan transaksi penjualan. Metode Penelitian yang digunakan adalah metode R \& D (Research and Development) yang digunakan untuk menghasilkan produk tertentu dan menguji kefektifannya. Metode Research and Development ini menghasilkan produk penelitian yang dapat digunakan untuk mengembangkan mutu pembelajaran secara efektif. Peneliti menarik kesimpulan bahwa sistem informasi yang telah dibuat dengan bahasa pemrograman Java Netbeans dapat membantu dalam melakukan kegiatan perusahaan yaitu transaksi penjualan instrumen bedan dan alat Kesehatan pada PT. Anugrah Dharma Bayu, sehingga proses transaksi penjualan dapat berjalan lebih cepat efektif dan efisien, juga dapat membantu dalam penyimpanan data transaksi dimana yang sebelumnya kurang aman penyimpanannya menjadi lebih amankarena data tersimpan kedalam database MySQL, sehingga semua proses dan informasi data yang dibutuhkan dapat dilakukan dengan cepat, kerusakan dan rawannya kehilangan data kemungkinan akan lebih sedikit.
\end{abstract}

Kata Kunci: Sistem Informasi Penjualan, Alat Kesehatan, Java

\begin{abstract}
Technology development is multiplying, especially computer information technology, encouraging the emergence of innovations in various information presentations to meet daily needs. The information system has many advantages, including data storage, time-saving, more efficiency, fast and precise. This study aims to create a design model of information system sales of surgical instruments and medical devices at PT. Anugrah Dharma Bayu is efficient, effective and helps company employees in conducting sales transactions. The research method used is Research and Development method used to produce specific products and test their effectiveness. This Research and Development method produces research products that use to develop learning quality effectively. The researcher concludes that the information system that has been created with the Java Netbeans programming language can assist in carrying out company activities, namely sales transactions for surgical instruments and medical devices at PT. Anugrah Dharma Bayu, so that the sales transaction process can run more quickly, effectively and efficiently, can also help in storing transaction data where previously less secure storage becomes more secure because the data is stored in the MySQL database, so that all processes and data information needed can be done quickly, the damage and prone to data loss is likely to be less.
\end{abstract}

Key Word: Selling information system, Medical devices, Java

\section{PENDAHULUAN}

Sistem informasi penjualan adalah sistem informasi yang menyangkut pengolahan data penjualan. Sistem informasi ini menyajikan suatu proses yang lebih efisien dan akurat dari pada proses konvensional. Digitalisasi dapat meningkatkan kinerja perusahaan dalam pengolahan data penjualan. Sistem informasi merupakan gabungan antara sistem dan informasi. Menurut Kadir dalam (Hidayat, 2019) Sistem adalah sekumpulan elemen yang saling terkait atau terpadu yang dimaksudkan untuk mencapai tujuan. Model umum sebuah sistem terdiri dari input, proses, dan output (Sutabri, 2012). Sedangkan (Hutahaean, 2015) mengatakan bahwa informasi adalah data yang diolah menjadi bentuk yang berguna dan lebih berarti bagi penerimanya. Prabowo (2020), menjelaskan secara umum bahwa informasi dapat diartikan sebagai data yang memiliki nilai kebergunaan. Menurut Jogiyanto dalam(Prehanto, 2020), informasi 
dapat dikatakan berkualitas jika memenuhi tiga aspek yaitu diantaranya akurat (accurate), tepat waktu (timeliness), dan relevan (relevance). Penulis mencoba menganalisis kekurangan ini untuk membantu mempermudah dalam pengolahan data penjualan berdasarkan Purchase Order (PO). Hal itu secara otomatis dapat mendata transaksi keluar yang sudah di-input. Sistem ini dapat membantu mempermudah dalam menemukan harga barang dengan hanya memasukan kode barang yang sudah di-input terlebih dahulu ke dalam data base untuk membuat tanda terima barang, selain membuat tanda terima barang, faktur barang dan invoice dapat dilengkapi dengan tanggal transaksi, nomor transaksi, dan jumlah tagihan yang harus dibayar, pembuatan laporan juga dipermudah karena sudah diinput tanda terima barang, faktur barang dan invoice.

Saat ini banyak perusahaan yang berdiri membuat persaingan usaha semakin ketat. Setiap perusahaan berlomba-lomba untuk memberikan pelayanan yang terbaik dengan kecocokan data yang cepat dan akurat. PT. Anugrah Dharma Bayu (ADB) sebagai suatu perusahaan yang bergerak di bidang penjualan instrumen bedah dan alat kesehatan dalam kegiatannya membutuhkan efesiensi dalam pengolahan data dan kemudahan dalam melakukan proses pendataan transaksi penjualan agar tidak terjadi kesalahan data. Sistem pencatatan dan pendataan transaksi penjualan yang masih menggunakan Ms Excel menyebabkan beberapa kerugian dalam kesalahan input harga dan keamanan data yang masih sangat kurang sehingga rawan rusak, mudah hilang, dan penyimpanan data yang dicetak terlalu banyak dapat memenuhi ruangan penyimpanan gudang. Sering terjadi kesalahan dalam memasukan harga barang serta kehilangan data invoice di PT. Anugrah Dharma Bayu karena pendataan transaksi masih didata menggunakan Ms Excel dimana penyimpanan data hanya di folder dan besar kemungkinan tercetak nomor transaksi sama pada tanda terima barang, faktur barang, dan invoice karena masih memasukan nomor transaksi diketik dengan tangan tidak otomatis, sehingga membuat kerancuan dalam pencarian data penjualan pada saat administrator melakukan proses laporan keuangan. Dengan begitu, administrator belum bisa menyajikan data yang tepat dan akurat.

Dengan adanya teknologi informasi maka sangat membantu pelaksanaan pendataan transaksi penjualan yang lebih efisien dan akurat. Oleh karena itu penulis tertarik untuk melakukan penelitian dengan judul aplikasi sistem informasi penjualan instrumen bedah dan alat Kesehatan pada PT. Anugrah Dharma Bayu. Penulis membuat sistem berbasis Java Netbeans. Hastuti dan Arief (2018) menjelaskan bahwa Netbeans adalah sebuah Integrated Development Environment atau IDE yang sangat tangguh untuk membuat aplikasi berbasis java serambi pengembangan perangkat lunak yang ditulis dalam bahasa pemrograman java. Pada proses pembuatan aplikasi ini, perangkat lunak yang digunakan adalah XAMPP. Menurut Sembiring (2020) XAMPP adalah perangkat lunak bebas yang mendukung banyaksistem operasi dan merupakan kompilasi atau gabungan dari beberapa program. Untuk penyimpanan file atau basis datanya, digunakan MySQL. Menurut Lubis (2016), basis data merupakan sekumpulan file data yang dibentuk dengan hubungan atau relasi yang logis dan dapat diungkapkan dengan catatan bersifat independen.

Penelitian yang serupa juga telah dilakukan oleh Fery Wongso pada tahun 2015 mengenai Perancangan Sitem Informasi Penjualan Berbasis Java Studi Kasus pada Toko Karya Gemilang Pekanbaru. Berdasarkan penelitian tersebut diperoleh membantu karyawan ataupun pemilik toko dalam mengelolah data dengan cepat, tepat dan akurat.(Wongso, 2015)

Tujuan dari penelitian ini adalah untuk mempermudah pengguna dalam menyajikan data yang tepat dan akurat. Dengan membangun sistem informasi dengan menggunakan Java dan Netbeans. Dengan menggunakan database MySql agar datanya aman dan tidak mudah hilang. Mengimplementasikan penggunaan sistem informasi menggunakan java dan database MySql untuk membuat kegiatan penjualan PT. Anugrah Dharma Bayu bejalan lebih efisien. 


\section{METODE PENELITIAN}

Desain penelitian ini merupakan kerangka atau perincian prosedur kerja yang akan dilakukan pada waktu meneliti, sehingga diharapkan dapat memberikan gambaran jika penelitian itu telah jadi atau selesai penelitian tersebut diberlakukan. Dalam hal ini penulis menggunakan metode penelitian pengembangan atau R\&D (Research and Development) dalam melakukan penelitian.

Metode penelitian dan pengembangan (research and development) adalah metode penelitian yang digunakan untuk menghasilkan produk tertentu dan menguji keefektifannya (Purnama, 2016).

Dimana Langkah-langkah yang dilakukan penulis adalah menganalisa permasalahan yang ada lalu mengumpulkan data yang dibutuhkan dan setelahnya dilakukan analisa perancangan dan pengembangan system.

Dalam melakukan penelitian, penulis menggunakan model pengembangan sistem waterfall. Model waterfall atau model air terjun adalah pendekatan SDLC (Sistem Development Life Cycle) yang paling awal digunakan untuk pengembangan perangkat lunak. Dalam model ini, setiap fase harus diselesaikan sebelum fase berikutnya dapat dimulai dan tidak ada fase yang tumpang tindih. Model waterfall ini sangat mudah dimengerti dan digunakan.

Rancangan kegiatan dimulai pada bulan April 2021 dengan kunjungan langsung ke lapangan untuk mencatat hal-hal penting sesuai dengan masalah. Metode pengumpulan data menggunakan 3 (tiga) cara, yaitu :

\section{Studi Lapangan}

Studi lapangan dilakukan untuk dapat melihat langsung sistem dan proses-proses kegiatan yang berjalan pada PT. Anugrah Dharma Bayu. Dalam studi lapangan ini pengumpulan data dilakukan dengan menggunakan teknik antara lain :

1. Wawancara

Teknik pengumpulan data dengan bertanya kepada pihak terkait dalam sistem PT. Anugrah Dharma Bayu pada bagian administrasi dan manajer operasional. Pertanyaan yang diajukan adalah seputar proses transaksi penjualan pada PT. Anugrah Dharma Bayu.

2. Observasi

Dalam melakukan observasi, penulis mengamati dan mempelajari bagaimana proses kegiatan pada PT. Anugrah Dharma
Bayu secara langsung. Penulis juga terlibat langsung dalam proses kegiatan tersebut sehingga dapat memahami bagaimana kegiatan yang berjalan. Hasil obeservasi kemudian dicatat untuk dapat dijadikan bahan dalam penelitian.

\section{Studi Kepustakan}

Studi kepustakan dilakukan untuk dapat mengambil referensi dari kutipan dari bukubuku, mengamati hasil laporan peneliti lain dan artikel - artikel yang mendukung dan berkaitan dengan penilitian ini. Referensi tersebut akan dijadikan sebagai landasan untuk dapat membantu dalam melakukan penelitian.

\section{Dokumentasi}

Dokumentasi dilakukan untuk mencari dan melihat serta mencatat data yang mana bersumber dari dokumen atau arsip PT. Anugrah Dharma Bayu yang berkaitan dengan penelitian yang dilakukan.

\section{HASIL DAN PEMBAHASAN}

Dari hasil penelitian yang peneliti lakukan, sistem informasi data transaksi penjualan di PT. Anugrah Dharma Bayu masih menggunakan sistem manual yaitu Microsoft Excel, dimana terdapat masalah-masalah yang timbul dalam sistem informasi diantaranya :

1. Sistem yang berjalan atau yang ada saat ini masih manual dan belum terkomputerisasi dimana masih kurang efektif untuk informasi pendataan perusahaan.

2. Kelambatan penyajian informasi tentang transaksi-transaksi penjualan.

3. Data file maupun dokumentasi untuk perusahaan masih menumpuk dan tidak tersusun rapi, yang mana menyebabkan sulit untuk pengecekan dokumen sewaktuwaktu dibutuhkan, dan membuat kesulitan bagi karyawan untuk mencari informasi berkaitan dengan data-data dalam perusahaan.

4. Banyak file yang tidak terorganisir sehingga dapat mengakibatkan kekeliruan dan kesalahan informasi Laporan dan kehilangan data.

Berdasarkan permasalahan yang disebutkan di atas, maka perusahaan ini memerlukan sebuah sistem informasi yang terkomputerisasi. Sehingga permasalahan yang terjadi dalam perusahaan yang sedang berjalan saat ini dapat teratasi. Dan diharapkan dengan adanya sistem yang terkomputerisasi proses usaha 
perusahaan dapat berjalan dengan lebih cepat, efektif, dan terorganisasi dengan baik.

\section{Diagram Konteks}

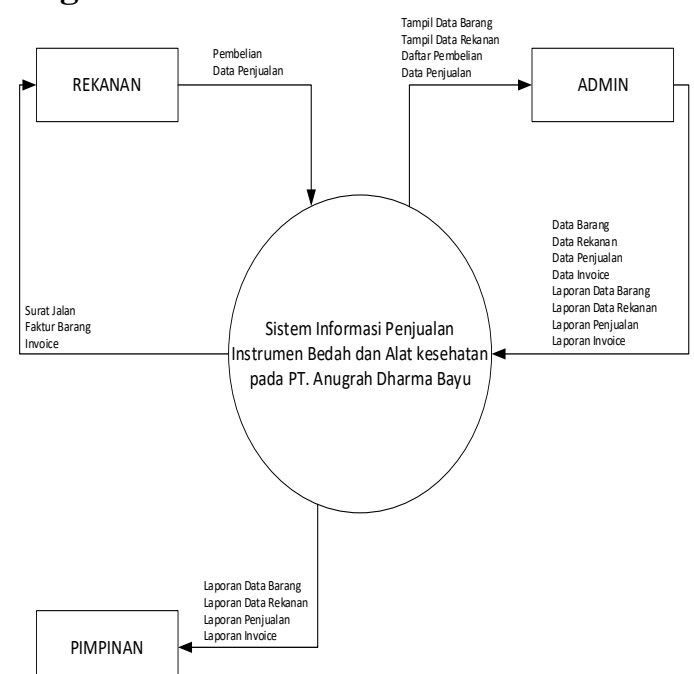

Gambar 1. Diagram Konteks Sistem Berjalan

\section{Entity Relationship Diagram (ERD)}

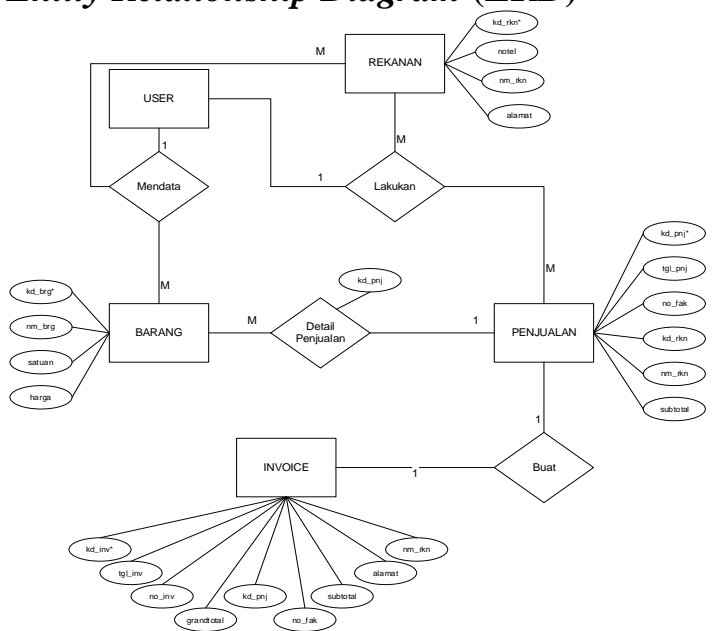

Gambar 2. Entity Relationship Diagram (ERD)

\section{Tampilan Menu Login}

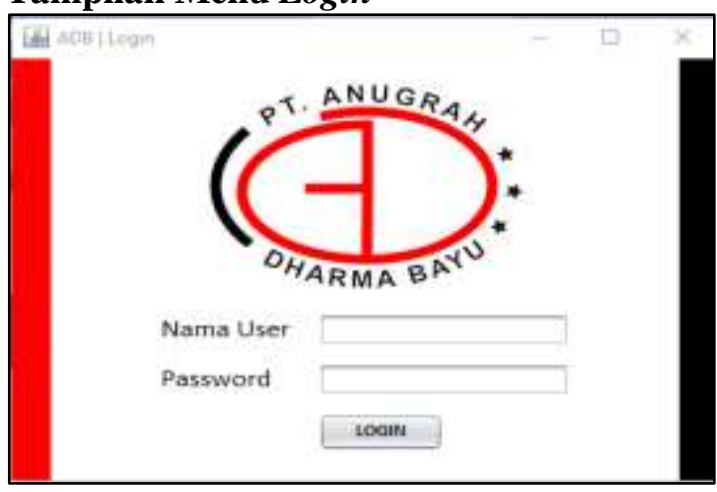

Gambar 3. Tampilan Layar Login

Layar Login ini akan muncul pada saat pertama kali aplikasi dijalankan. Pada layer ini pengguna akan diminta untuk memasukan nama user dan password yang sesuai untuk mendapatkan akses masuk ke layar menu utama.

\section{Tampilan Menu Utama}

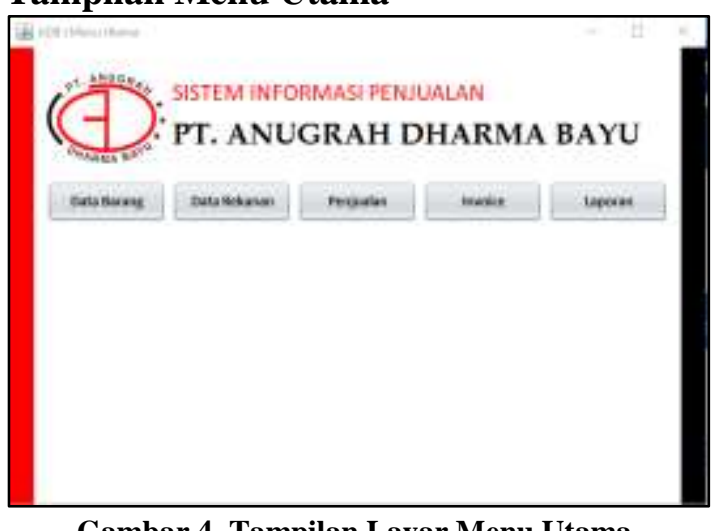

Gambar 4. Tampilan Layar Menu Utama

Tampilan layar menu utama ini akan muncul setelah pengguna berhasil mendapatkan akses dari layer login. Di dalam menu utama ini terdapat beberapa pilihan data yang diolah oleh aplikasi ini seperti data barang, data rekanan, penjualan, invoice, laporan.

\section{Tampilan Form Data Barang}

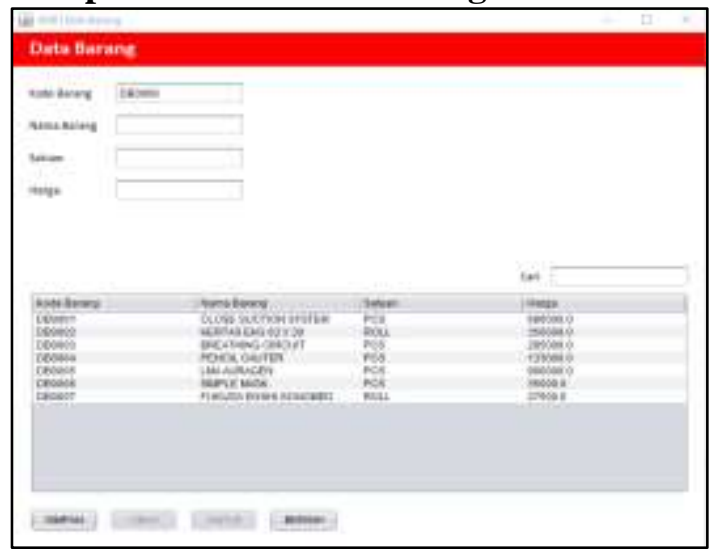

Gambar 5. Tampilan Form Data Barang

Tampilan layar form masukan data barang ini akan muncul setelah pengguna memilih pilihan data barang pada menu utama, dari tampilan form ini pengguna dapat mengisi form tersebut sesuai data list persediaan barang mulai dari kode barang, nama barang, satuan, dan harga, lalu klik simpan agar data barang dapat tersimpan pada database. Jika sudah tersimpan, pada tampilan form ini dapat mencari barang yang ingin diketahui hargnya maupun nantinya untuk proses transaksi penjualan dengan memasukan kode rekanan saja pada kolom cari. 


\section{Tampilan Laporan Data Barang}

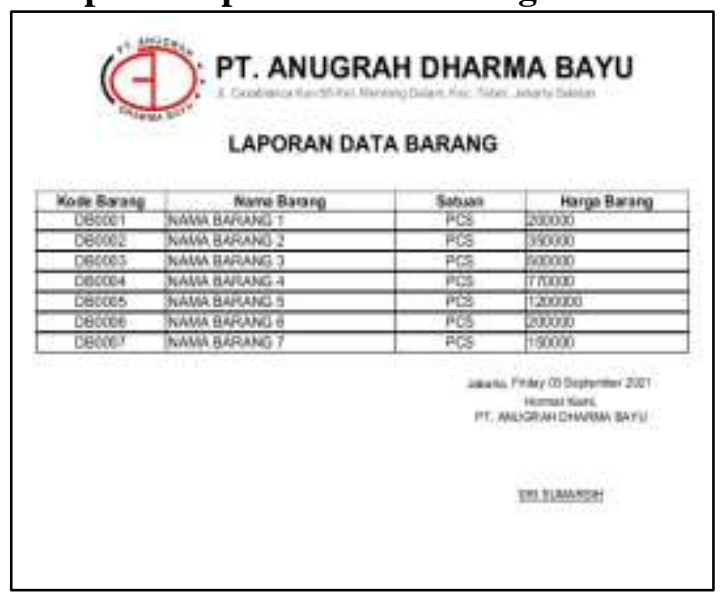

Gambar 6. Tampilan Laporan Data Barang

Tampilan layar form masukan data rekanan ini akan muncul setelah pengguna memilih pilihan data rekanan pada menu utama, dari tampilan form ini pengguna dapat mengisi form tersebut sesuai data rekanan yang diberikan oleh rekan perusahaan untuk proses transaksi penjualan nantinya, pengguna dapat mengisi form mulai dari kode rekanan, nama rekanan, no. telepon, dan alamat, lalu klik simpan agar data barang dapat tersimpan pada database. Jika sudah tersimpan, pada tampilan form ini dapat mencari identitas rekanan dengan memasukan kode rekanan saja pada kolom cari.

\section{SIMPULAN DAN SARAN}

Berdasarkan hasil dan pembahasan penelitian ini, penulis menyimpulkan bahwa :

1. Dengan adanya sistem informasi yang dibuat dengan menggunakan bahasa pemrograman Java maka akan membuat kegiatan pejualan yang tadinya masih menggunakan Ms Excel yang dimana input masih diketik menjadi sebuah sistem yang terkomputerisasi.

2. Sistem informasi yang dibangun menggunakan database MySql yang dapat menyimpan data secara terstruktur dan juga aman serta tidak mudah hilang.

3. Dengan adanya fitur pencarian pada sistem informasi yang mana terintegrasi dengan database akan memudahkan pencarian dan penyajian data penjualan dengan mudah, cepat, dan akurat.

4. Dengan mengedukasi pengguna untuk beralih menggunakan sistem informasi ini agar dapat menunjang kegiatan dan memenuhi kebutuhan perusahaan PT. Anugrah Dharma Bayu.
Sejalan dengan system ususlan yang penulis buat, demi tercapainya tujuan dan sasaran yang diharapkan, maka penulis dapat memberi saran sebagai berikut :

1. Aplikasi penjualan alat kesehatan dan instrumen bedah pada PT. Anugrah Dharma Bayu dapat dikembangkan kembali dalam hal desain atau penambahan database sesuai dengan kebutuhan pengelolaan data.

2. Meskipun telah menggunakan sistem yang terkomputerisasi dengan database, ketelitian dalam meng-input data perlu diperhatikan agar data yang sudah di-input benar-benar merupakan salinan dari data sumber.

3. Keamanan sistem perlu dijaga dengan cara mempercayakan kepada pegawai yang bertanggung jawab.

\section{DAFTAR PUSTAKA}

Hastuti, D., \& Arief, Y. (2018). Belajar Pemrograman Java Menggunakan FX dan Database H2. Yogyakarta: Aswaja Pressindo.

Hidayat, F. (2019). Konsep Dasar Sistem Informasi Kesehatan. Yogyakarta: Deepublish.

Hutahaean, J. (2015). Konsep Sistem Informasi. Yogyakarta: Graha Ilmu.

Lubis, A. (2016). Basis Data Dasar. Sleman (Sleman). Yogyakarta: Deepublish.

Prabowo, M. (2020). Metodologi Pengembangan Sistem Informasi. Salatiga: LP2M IAIN Salatiga.

Prehanto, D. R. (2020). Buku Ajar Konsep Sistem Informasi. Surabaya: Scopindo Media Pustaka.

Purnama, S. (2016). Metode Penelitian Dan Pengembangan (Pengenalan Untuk Mengembangkan Produk Pembelajaran Bahasa Arab). LITERASI (Jurnal Ilmu Pendidikan), 4(1), https://doi.org/10.21927/literasi.2013.4( 1). 19-32

Sembiring, F. (2020). Fundamental Basis Data. Bandung: Media Sains Indonesia.

Sutabri, T. (2012). Konsep Sistem Informasi. Yogyakarta: CV. Andi Ooffset.

Wongso, F. (2015) "Perancangan Sistem Informasi Penjualan Berbasis Java Studi Kasus Pada Toko Karya Gemilang Pekanbaru." Jurnal Ilmiah Ekonomi dan Bisnis Unilak, vol. 12, no. 1. https://doi.org/10.31849/jieb.v12i1.813 